\title{
Identity concept formation during visual multiple- choice matching in a harbor seal (Phoca vitulina)
}

\author{
BJÖRN MAUCK and GUIDO DEHNHARDT \\ Ruhr-Universität Bochum, Bochum, Germany
}

\begin{abstract}
Identity concept formation was tested in a harbor seal using a visual multiple-choice matching-tosample task. The seal was first trained on a two-alternative matching task. After criterion ( $\geq 80 \%$ correct choices in two successive sessions) was reached with two sets of two stimuli (Figure 3, Blocks A and B), stimulus sets were enlarged to six objects (Blocks $C-G$ ). After the seal reached criterion immediately with two successive sets (Blocks F and G), multiple-choice matching was introduced, first using stimulus sets of four familiar objects (Blocks H-M). After the seal reached the criterion immediately with two successive sets (Blocks L and M), completely new objects were used in two further stimulus sets (Blocks $\mathrm{N}$ and $\mathrm{O}$ ). The seal immediately applied the matching rule in all four sessions ( $\geq 80 \%$ correct choices). In two further sessions with problems composed of all 38 familiar stimuli, the seal again reached the criterion (Block P). In the final, transfer session, 20 new problems were composed of 80 unknown stimuli (Block Q). The seal immediately applied the matching rule in these one-trial tests, showing that harbor seals can conceptualize complex visual information.
\end{abstract}

Many researchers have suggested that most daily problems marine mammals have to face in the wild, such as navigation on the high seas, predator avoidance, recognition of mating partners, and selecting, locating, and hunting palatable prey, might be solved more efficiently using concepts (see, e.g., Kastak \& Schusterman, 1992). Concepts are mental representations of classes that help organisms navigate through the maze of ever-changing stimuli in the world (Domjan, 1998) by promoting cognitive economy (Rosch, 1978). On the basis of abstraction and generalization, animals may form absolute or abstract concepts about their specific environment (Rensch, 1973) that may facilitate and hasten necessary decisions, and thus help them survive. The effects of information processing and decision making on survival, and thus on animal fitness, are a central issue of cognitive ecology, an approach that brings cognitive science and behavioral ecology together (Dukas, 1998; Healy \& Braithwaite, 2000; Real, 1993). Cognitive ecology both addresses ultimate questions about the optimal design of, constraints on, and function of cognitive traits, and generates hypotheses on related factors, such as the mechanisms underlying acquisition and manipulation of information. Viewed from the cognitive ecology perspective, the numerous studies on marine mammal cognition in general and on their capabilities to form concepts in particular (for re-

The experimental animal was treated in accord with the official German regulations for research on animals. We thank G. Nogge of Cologne Zoo for his support during this study. The Volkswagen Stiftung and the Deutsche Forschungsgemeinschaft supported this study through grants to G.D. Correspondence relating to this article may be sent to B. Mauck, Ruhr-Universität Bochum, Allgemeine Zoologie \& Neurobiologie, ND6/33, D-44780 Bochum, Germany (e-mail: mauck@neurobiologie .ruhr-uni-bochum.de). views, see Mobley \& Helweg, 1990; Renouf, 1991; Roitblat, 1987; Schusterman, 1981; Schusterman \& Kastak, 2002; Schusterman, Reichmuth Kastak, \& Kastak, 2002; Schusterman, Thomas, \& Wood, 1986) may provide valuable results indicating which psychological processes and mental representations marine mammals have developed to survive in their aquatic environment. However, although some of the concepts found up to now in marine mammals (such as equivalence; Schusterman, Reichmuth, \& Kastak, 2000) have been explained in terms of probable increases in fitness within the marine environment, others (such as symmetry; von Fersen, Manos, Goldowsky, \& Roitblat, 1992) have been considered to have no obvious evolutionary advantage.

Although the marine environment seems rather unstructured, at least with respect to visual cues, and concrete application scenarios in the wild seem difficult to conceive, the ability to discriminate "same" versus "different" has been mentioned, along with other abstract concepts, as being potentially helpful for marine mammals (Kastak \& Schusterman, 1992). In fact, the capability to form the corresponding concepts "identity" and "oddity" is probably the most tested conceptualization in marine mammals. These concepts are considered abstract because an animal has to discriminate objects on the basis of their relations to one another rather than on the basis of the presence or absence of some particular feature in the individual object. In the experimental context, the term identity concept thus refers to the animal's ability to match like with like in an appropriate experimental paradigm.

The formation of a concept of sameness (or of oddity) has often been tested using the matching-to-sample procedure (a special variant of the conditional discrimination task; Schusterman \& Kastak, 2002), which is also the basic experimental paradigm for many other cognitive tasks 
(see, e.g., Mauck \& Dehnhardt, 1997; Stich, Dehnhardt, \& Mauck, 2003). In this task, the animal's choice between two or more comparison stimuli is contingent on a sample stimulus presented either simultaneously with or before the comparison stimuli. In marine mammals, the matching procedure has been used both in auditory/ echolocation tasks (Harley, Roitblat, \& Nachtigall, 1996; Herman, Pack, \& Hoffmann-Kuhnt, 1998; Pack \& Herman, 1995) and in visual tasks with bottlenose dolphins (Herman, Hovancik, Gory, \& Bradshaw, 1989; Mercado, Killebrew, Pack, Mácha, \& Herman, 2000) or California sea lions (Kastak \& Schusterman, 1994; Pack, Herman, $\&$ Roitblat, 1991). However, although evidence for this kind of concept formation has been a matter of some controversy even for these two well-studied species (Kastak \& Schusterman, 1992; Schusterman \& Kastak, 1995), the few studies performed with other marine mammals up to now have failed to show reliable performance in either a conditional discrimination or matching procedure, and consequently have not presented evidence of concept formation. By training two harbor seals on spatial and visual matching-to-sample tasks, Renouf and Gaborko (1988, 1989) could not establish performance significantly different from chance level in the visual tasks. This dissociation in seals' ability to form spatial and visual concepts has been mainly attributed to ecological reasons, in that spatial information may be unusually important for this species, and the visual matching-to-sample paradigm might not be an appropriate vehicle for the demonstration of a sameness concept.

However, since harbor seals inhabit the same marine environment as sea lions and dolphins, it seems difficult to conceive why ecological reasons should be responsible for this species not being capable of visual concept formation (see also Hanggi \& Schusterman, 1995). Furthermore, although the practical benefits of a visual identity concept in the wild are not really compelling, the capability of detecting equality or inequality relations among events of diverse natures is generally considered an essential prerequisite for several forms of reasoning (Delius, 1994). Thus, an identity concept formation capability might in fact simply be indicative of a highly developed information processing system, and it might only be a question of choosing appropriate methods for showing identity concept formation. In fact, Hanggi and Schusterman concluded from their results that the standard methods used in teaching conditional discrimination, which are successful with sea lions, are not appropriate for harbor seals. Interestingly, these authors supposed that their harbor seal might have performed better if it had been given more than two choices in the matching task. Sidman (1987) had already suggested that two choices are not enough, because a subject's high performance $(75 \%$ correct choices or higher) could be attained not by choosing correctly on the basis of an appropriate stimulus but by exclusion, or even by biasing to one key position. On the other hand, using three or more comparison stimuli-one correct and two or more incorrect-fosters selection by choice, not by exclusion. Exclusion would require the subject to learn two or more relations, whereas choosing on the basis of the correct stimulus would require only one.

By using more appropriate methods, such as a multiplechoice matching task, we might expect to show the capability of identity concept formation in some animal species that have been assumed to be incapable of this conceptualization. Therefore, we tested whether a harbor seal could perform a visual multiple-choice matching task at a level indicative of identity concept formation.

\section{METHOD}

\section{Test Animal}

The study was conducted with a 4-year-old male harbor seal (Phoca vitulina vitulina) named Malte at our Marine Mammal Research Lab at Cologne Zoo, Germany. Malte had been a subject in a study on hydrodynamic trail following but was experimentally naive concerning visual tasks. The seal was born in captivity and was housed with 8 other harbor seals in a spacious enclosure consisting of two interconnected pools with a total volume of about $1,000 \mathrm{~m}^{3}$ of fresh water and adjacent land parts. Malte was fed $2-5 \mathrm{~kg}$ of freshly thawed cut herring supplemented with vitamins; about half of the seal's daily diet was fed during the experiments. Experiments were typically conducted 5 days per week, and the seal experienced routine food deprivation of $12-18 \mathrm{~h}$ between the last feeding in the late afternoon and the next day's experiments. During experimental sessions, Malte was separated from the other seals.

\section{Apparatus and Procedure}

The test apparatus was designed for the presentation of threedimensional stimuli (toys and junk objects; see Figures 1A and 1B) in a matching-to-sample procedure. These objects were diverse with respect to such parameters as size, shape, color, material, surface texture, and orientation. The 20 objects used as correct stimuli in the one-trial transfer tests of Block Q (marked by asterisks in Figure 1B) did not share any systematic parameter (e.g., a common brightness, size, or other quality) that would allow the application of simple stimulus generalization rules. The apparatus was installed at the edge of a pool, and the seal could easily approach it by swimming in the shallow water in front of the apparatus (Figure 2). The upper part of the apparatus consisted of a slightly inclined metal frame holding an opaque PVC plate $(2 \times 2.5 \mathrm{~m})$ that allowed the experimenter to hide from the seal's sight in order to avoid giving any unintentional cues. During trials, the seal could be observed in a mirror installed behind it on the wall next to the apparatus. In the lower part of the apparatus, a box was installed with three windows covered by metal shutters running side by side. The shutters could be raised and lowered manually by the experimenter using a pulley system fixed to the upper frame. The central shutter could be moved independently of the side shutters. Behind the shutters, stimuli mounted on thin rods could be placed equally distant from each other in short metal tubes. In the two-alternative matching-to-sample task, one comparison stimulus was placed on each side of the sample, which was presented at the central position. For multiple-choice matching, two comparison stimuli were presented on each side of the sample. In front of the apparatus, a hoop station for the seal was installed in order to ensure that the seal would keep a constant distance of $1 \mathrm{~m}$ from the apparatus when stimuli were presented.

At the beginning of a trial, the stimuli were mounted behind the three windows of the apparatus, starting always from the left side, and the experimenter stood behind the apparatus in order to avoid giving the animal any cues. The seal was allowed to move freely in 


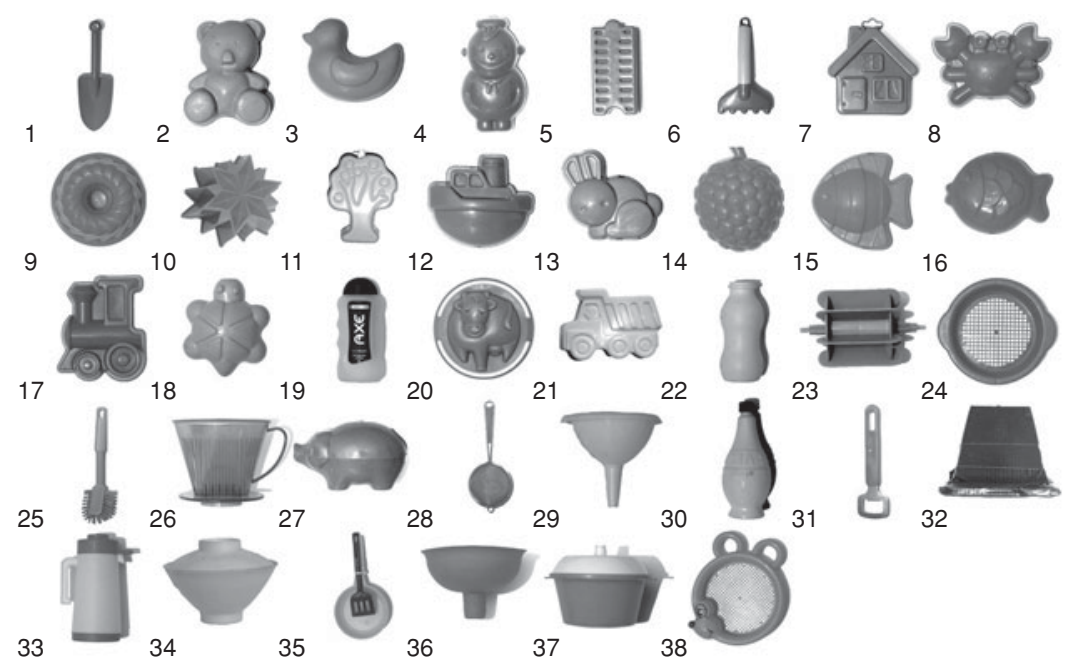

Figure 1A. Stimuli used in Blocks A-P of the study (not to scale).

the pool between trials. Stepping beside the apparatus, the experimenter then gestured the seal to position its head in the stationing hoop facing the apparatus. As soon as the animal reached its position in the stationing hoop, the experimenter hid again behind the apparatus; from now on, the seal was observed using the observation mirror. A trial was started by the experimenter raising the central shutter, whereupon the sample became visible in the middle of the apparatus. After the sample had been shown for $5 \mathrm{sec}$, the experimenter raised both side shutters, thereby presenting the comparison stimuli (two comparison stimuli in two-alternative matching, four in multiplechoice matching). Only one of the comparison stimuli was identical to the sample object. The appearance of the comparison stimuli was the signal for the seal to choose. After leaving the hoop, the animal had to approach the apparatus (see Figure 2) and press its snout first against the sample and then against one of the comparison objects. The seal was rewarded for responding to the stimulus matching the sample. Correct choices were rewarded with pieces of cut herring; there was no punishment for incorrect choices.

\section{Stages of the Study}

Since the animal was experimentally naive concerning visual tasks, it had to get acquainted both with the experimental procedure and with the matching task. For this reason, the study was subdivided into three stages - namely, two-alternative matching, multiplechoice matching, and final transfer testing in a session composed of problems with stimuli that appeared for one trial only (see Table 1).

Throughout the experiment, the position of the correct comparison stimulus $(\mathrm{S}+)$ and the number of trials in which each of the objects was used as the correct and as an incorrect $(\mathrm{S}-$ ) comparison stimulus were balanced over a session. The objects used as $\mathrm{S}+$ and $\mathrm{S}-$ were also balanced over a session, and the sequence in which objects appeared as $\mathrm{S}+$ and $\mathrm{S}-$ followed a pseudorandom schedule (Gellerman, 1933). The learning criterion was defined as $\geq 80 \%$ correct choices in two successive sessions ( $\chi^{2}$ test, $p<.001$, for all numbers of trials per session), but to further establish the seal's performance during acquisition or to increase the seal's motivation, more sessions were allowed after the animal had reached the criterion.

During the first experimental stage, a two-alternative matching task was trained (Figure 3, Blocks A-G, and Table 1). In the first two blocks of sessions (A and B), the seal had to perform the matching task with only two objects in each block. The first five sessions of Block A consisted of 50 trials, but because of the seal's poor motiva- tion, especially at the end of a session, this was reduced to 40 trials for the remaining sessions of Block A and for Block B.

During the next five blocks of sessions $(\mathrm{C}-\mathrm{G})$, the seal had to master the two-alternative matching procedure with stimulus sets of six new objects (except for Block D, where - because of poor motivationonly two new objects were presented, together with four familiar objects). Objects were presented in 60 trials per session. These trials covered all possible combinations of sample and comparison stimuli and of the respective positions of S + and S- (left vs. right).

During the second experimental stage, multiple-choice matching with four objects was introduced (Figure 3, H-P; also used in final transfer test Q). In a four-alternative matching procedure, the subject's probability to choose correctly by chance is only .25. Although this also reduced the statistic criterion for performance significantly different from chance (39.58\% correct choices for 96 trials in Blocks $\mathrm{H}-\mathrm{O}, 53.33 \%$ for 30 trials in Block P, and $60 \%$ for 20 trials in Block Q; significance level of $p<.001, \chi^{2}$ test), we nevertheless decided to maintain the learning criterion of $\geq 80 \%$ correct choices in two successive sessions. In Blocks $\mathrm{H}-\mathrm{M}$, problems in each block were composed using stimulus sets of four objects already known to the seal from the two-alternative matching. Objects were presented in 96 trials for each session. Again, these trials covered all possible combinations of sample stimulus and the positions of the four comparison stimuli (one $\mathrm{S}+$ and three $\mathrm{S}-$ ).

In Blocks $\mathrm{N}$ and $\mathrm{O}$, two sets of four new objects were introduced. Composition of the sessions, number of trials, and sequence of the problems were as described for Blocks $\mathrm{H}-\mathrm{M}$.

Block P consisted of two sessions meant as a preparation for the final transfer test, which would involve a large set of new stimuli. Thus, to get the seal used to a large pool of stimuli, all 38 familiar objects were used in Block P. However, to avoid presenting these already familiar stimuli too often, only 30 trials were performed per session. From the pool of all possible combinations of objects as $\mathrm{S}+$ and $\mathrm{S}-$ and all positions of the four comparison stimuli (one $\mathrm{S}+$ and three $\mathrm{S}-$ ), problems were chosen following a pseudorandom pattern.

In the final transfer test (Block Q), 80 new objects were introduced in a session of 20 problems. Each problem consisted of two identical objects (the sample stimulus and correct comparison stimulus $\mathrm{S}+$ ) and three other objects that neither resembled the sample nor each other (incorrect comparison stimuli S-). All objects were unfamiliar to the seal and were used only once (one-trial problems). 


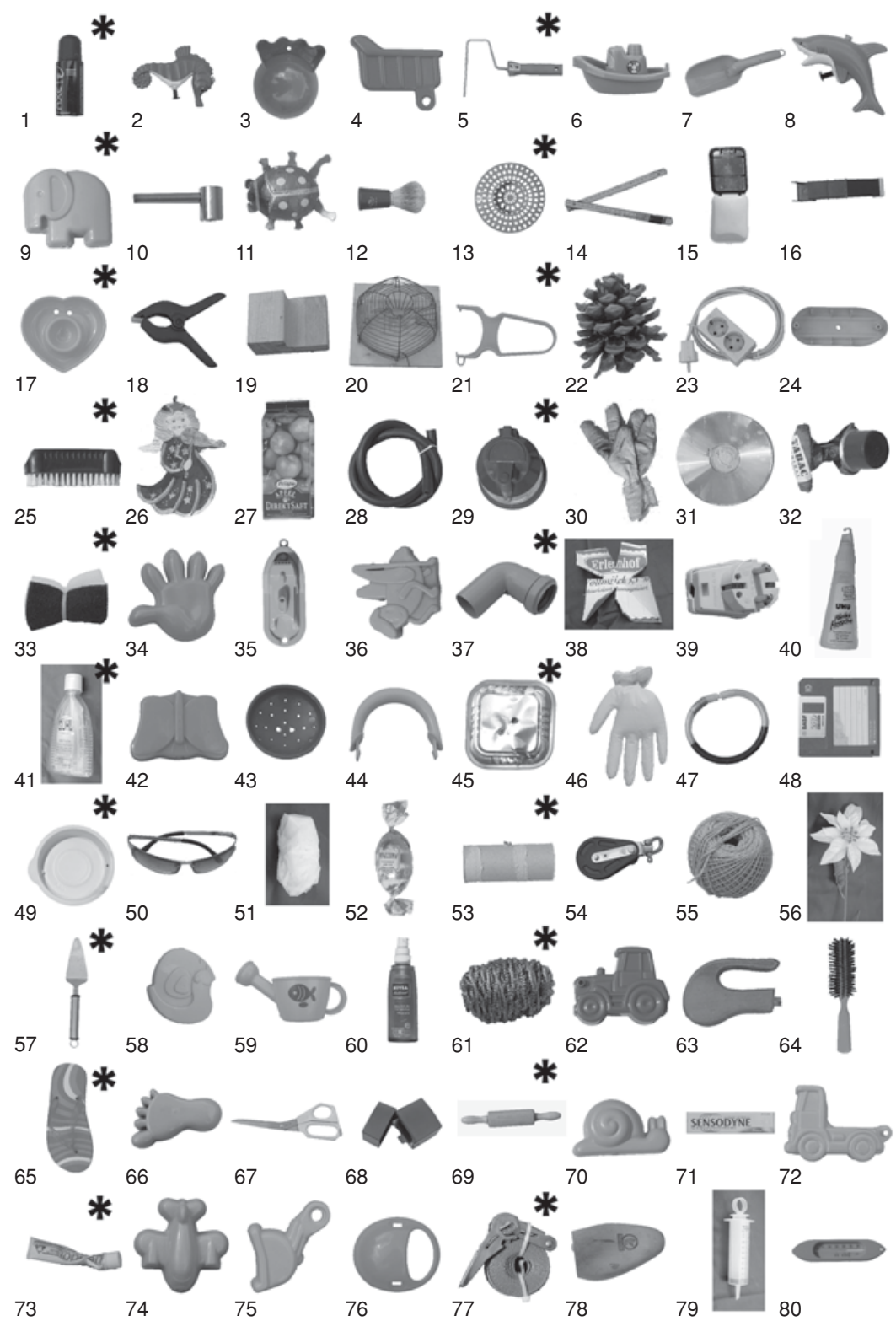

Figure 1B. The 80 new stimuli used in Block $Q$ (transfer test with one-trial problems; not to scale). Objects used as the sample stimuli are marked with asterisks; the three objects to the right of each sample were its noncorrect comparison stimuli. Note that some of the bright objects are photographed against a dark background, which was not part of the stimulus.

\section{RESULTS}

Since the seal was used to basic conditioning techniques, it learned the basic experimental procedure (stationing in the hoop, approaching the apparatus, and touching the objects with its snout) with little difficulty.

Trials were mostly completed within about $30 \mathrm{sec}$, during which the seal approached the apparatus, touched the sample with its snout, and chose one of the comparison stimuli shortly after. Sometimes the seal showed vicari- ous trial-and-error behavior by looking to and fro between the comparison stimuli and only then making a choice by touching one of the stimuli with its snout. The seal was never observed turning around to look in the mirror to detect cues unintentionally given by the experimenter; rather, the seal ignored the existence of the mirror. Between trials, the seal normally swam around in the pool, only approaching the experimental setup when it was called.

During the first experimental stage (two-alternative matching; Figure 3, Blocks A-G), the seal reached the cri- 


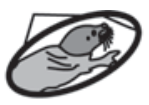

Observation mirror installed at the wall next to the apparatus

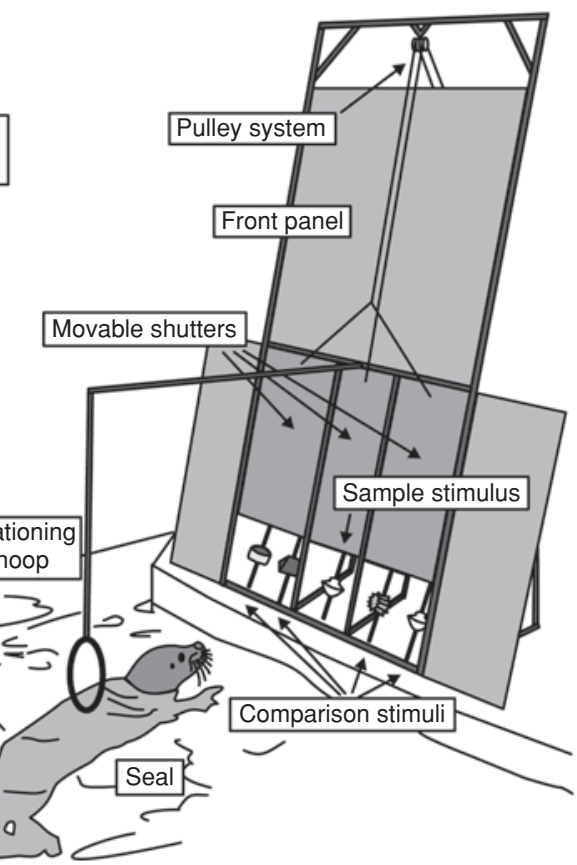

Figure 2. Schematic drawing of the experimental setup. Here, the multiple-choice matching setup is shown (two comparison stimuli on each side of the sample stimulus). For the two-alternative matching task, only one comparison stimulus was mounted on each side of the sample stimulus.

terion with the first two objects within 10 sessions (Block A), but it needed 21 sessions to reach the criterion when two new objects were introduced (Block B).

In the following five blocks of sessions $(\mathrm{C}-\mathrm{G})$, the seal had to master the two-alternative matching procedure with stimulus sets of six objects. In the fourth and fifth of these blocks ( $\mathrm{F}$ and $\mathrm{G}$ ), the seal reached $\geq 80 \%$ correct choices with sets of completely new stimuli in the first session and maintained this performance in the second session.

In the second experimental stage (Figure 3, Blocks H-P), the task was changed to multiple-choice matching with four objects. In Blocks H-M, problems were composed using stimulus sets of four familiar objects in each block. The seal reached $>80 \%$ correct choices in the very first

Table 1

Experimental Stages of the Study

\begin{tabular}{|c|c|c|c|c|c|c|}
\hline Block & $\begin{array}{l}\text { Number } \\
\text { of Choices }\end{array}$ & $\begin{array}{l}\text { Number } \\
\text { of Stimuli }\end{array}$ & $\begin{array}{c}\text { Number } \\
\text { of Sessions }\end{array}$ & $\begin{array}{c}\text { Number of } \\
\text { Trials/Session }\end{array}$ & $\begin{array}{l}\% \text { of Correct Choices for } \\
\text { Significant Performance* }\end{array}$ & $\begin{array}{c}\text { Learning } \\
\text { Criterion }(\%)\end{array}$ \\
\hline A & 2 & 2 new & 11 & 50 or 40 & 77.50 & 80 \\
\hline B & 2 & 2 new & 22 & 40 & 77.50 & 80 \\
\hline $\mathrm{C}$ & 2 & 6 new & 10 & 60 & 71.67 & 80 \\
\hline $\mathrm{D}$ & 2 & 6 partly new & 4 & 60 & 71.67 & 80 \\
\hline $\mathrm{E}$ & 2 & 6 new & 3 & 60 & 71.67 & 80 \\
\hline $\mathrm{F}$ & 2 & 6 new & 3 & 60 & 71.67 & 80 \\
\hline G & 2 & 6 new & 2 & 60 & 71.67 & 80 \\
\hline $\mathrm{H}$ & 4 & 4 familiar & 17 & 96 & 39.58 & 80 \\
\hline $\mathrm{I}$ & 4 & 4 familiar & 7 & 96 & 39.58 & 80 \\
\hline $\mathrm{J}$ & 4 & 4 familiar & 5 & 96 & 39.58 & 80 \\
\hline $\mathrm{K}$ & 4 & 4 familiar & 3 & 96 & 39.58 & 80 \\
\hline $\mathrm{L}$ & 4 & 4 familiar & 2 & 96 & 39.58 & 80 \\
\hline M & 4 & 4 familiar & 2 & 96 & 39.58 & 80 \\
\hline $\mathrm{N}$ & 4 & 4 new & 2 & 96 & 39.58 & 80 \\
\hline $\mathrm{O}$ & 4 & 4 new & 2 & 96 & 39.58 & 80 \\
\hline $\mathrm{P}$ & 4 & 38 familiar & 2 & 30 & 53.33 & 80 \\
\hline Q & 4 & 80 new & 1 & 20 & 60.00 & 80 \\
\hline
\end{tabular}

*According to chi-square test $(p<.001)$. 


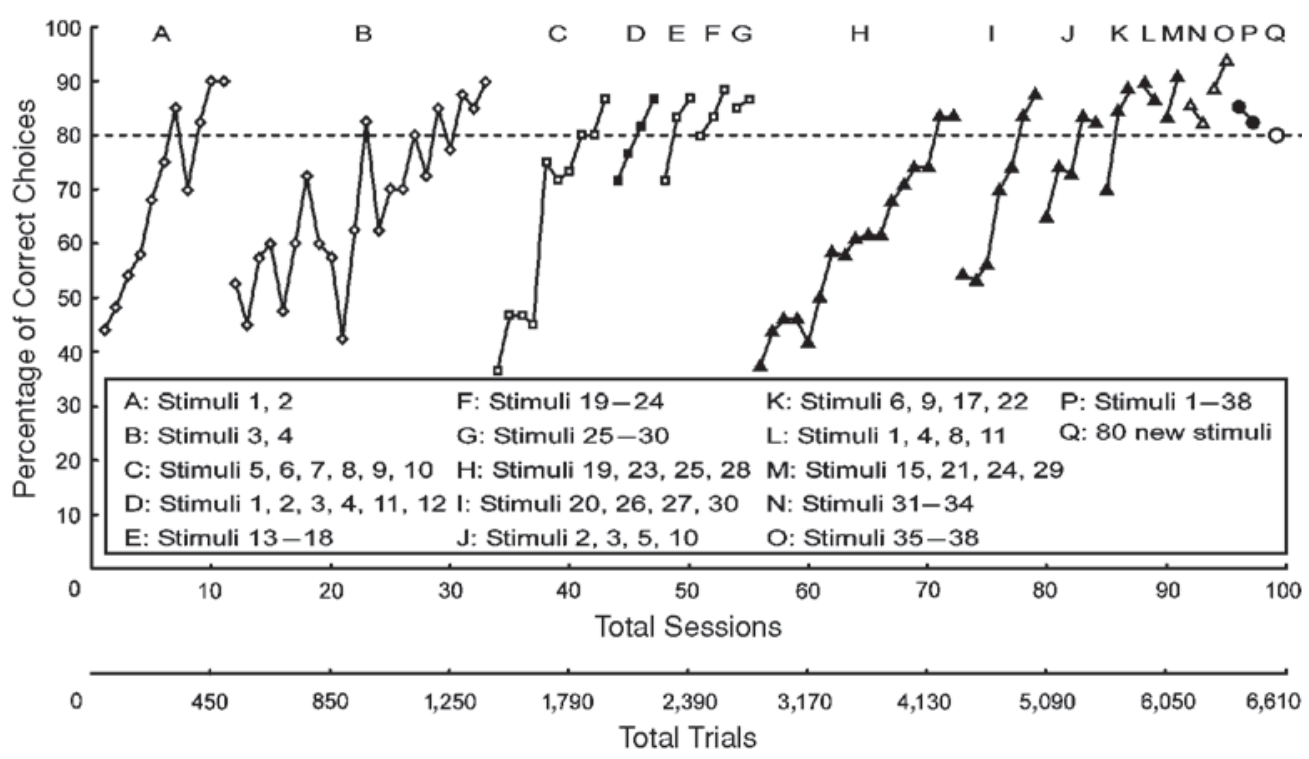

Figure 3. Learning curves of our harbor seal. (Blocks A-G) Performance in experiments with twoalternative matching. (Blocks $\mathrm{H}-\mathrm{Q}$ ) Performance in experiments with multiple-choice matching. Stimulus numbers used in each block are given in the insert and refer to the stimuli shown in Figures 1A and 1B. Open symbols represent sessions with completely new stimuli, and filled symbols represent sessions with stimuli at least partly familiar to the seal.

session in Blocks $\mathrm{L}$ and $\mathrm{M}$ and maintained this performance in each second session.

With sets of four new objects in Blocks $\mathrm{N}$ and $\mathrm{O}$, the seal reached $>80 \%$ correct choices in each first session and maintained this performance in the second session.

In Block P (38 familiar objects), the seal also showed performance of $>80 \%$ correct choices in both sessions.

In the final transfer test (Block Q), the seal immediately applied the matching rule to the 80 new stimuli ( $80 \%$ correct choices, $\chi^{2}$ test; $\left.\chi^{2}=32.3, p<.001\right)$.

\section{DISCUSSION}

\section{The Seal's Performance During the Study}

Although experimentally naive concerning visual tasks and cognitive test paradigms, our seal learned the matching procedure with little difficulty. It steadily increased its performance in the first block with two objects and mastered the discrimination within 10 sessions (450 trials). Performance with these first two objects already indicated that our harbor seal would learn visual discrimination tasks on an efficiency level similar to the one known from studies with California sea lions. In a study on mental rotation using an identity matching procedure, it took our sea lion 10 sessions to learn the initial discriminations between two stimuli (240 trials to criterion; Mauck \& Dehnhardt, 1997). In a study by Pack et al. (1991), the performance of a California sea lion with the first three stimuli used during the acquisition stage of a matching experiment increased within the first 24 sessions ( 503 trials), but the sea lion only reached the defined criterion after the third stimulus was eliminated from the object pool in an additional 269 trials. In contrast, most harbor seals tested in visual cognitive tasks up to now have performed clearly more poorly. Both harbor seals used in Renouf and Gaborko's (1988) study did not reach the second training stage after 24 and 23 sessions, respectively (i.e., totals of 1,800 and 1,725 trials). On the best 30 trials, the performance of these seals was $57.4 \%$ and $56.9 \%$ correct choices, respectively, and neither seal showed any evidence of improvement. However, some harbor seals do finally succeed in basic discrimination tasks, although with obvious difficulties. In a follow-up study by Renouf and Gaborko (1989), one harbor seal seemed unable to learn a black/white discrimination in a matching task, but the other seal needed 19, 15, 20, 4, and 7 sessions (50 trials each) to reach the criterion of $90 \%$ correct choices in the best 30 trials for the five successive tasks (i.e., 950, $750,1,000,200$, and 350 trials, respectively). The harbor seal tested by Hanggi and Schusterman (1995) in a conditional discrimination paradigm reached the criterion with the first two sample/comparisons only after 2,720 trials (68 sessions, 40 trials each).

In the second block of sessions of the present study (Block B), our harbor seal needed 21 sessions (840 trials) to reliably perform the matching procedure with two new objects, which is in the same order of magnitude as the learning progress of our sea lion during the application of the matching-to-sample procedure to the first mirrorimage discriminations (Mauck \& Dehnhardt, 1997). During the initial blocks (A and B) of the present study, our harbor seal certainly used absolute stimulus parameters for discriminating the objects rather than identity relations between sample and comparison stimuli. During the fol- 
lowing blocks of sessions $(\mathrm{C}-\mathrm{G})$, we presented our harbor seal with stimulus sets of six new objects (except in Block $\mathrm{D}$, which included the stimuli already used in Blocks A and B). Here, the seal might have started to apply some kind of identity rule instead of using another strategy to solve the matching task, such as merely learning absolute stimulus parameters or perhaps forming simple if . . then rules, because performance increased from block to block insofar as the number of sessions to criterion decreased $(10,4,3,3$, and 2 sessions, respectively). This could be explained with Harlow's (1949) sense of the term learning set as "learning to learn," used to indicate that animals not only learn how to respond appropriately to individual problems but also can learn about the more general nature of problems and how to solve them efficiently (cf. Schusterman et al., 2002). Although a level of more than $80 \%$ correct choices was reached immediately in the first session of Block $\mathrm{G}$, and although the comparatively large number of stimuli introduced in this experimental stage (26 new objects) could have facilitated concept formation by this point, we nevertheless cannot exclude the possibility that the seal learned from the first few errors in a session (60 trials were conducted per session) and succeeded in the following trials on the basis of either exclusion or absolute stimulus parameters (for discussions of exclusion, see Kastak \& Schusterman, 1994; Schusterman, Gisiner, Grimm, \& Hanggi, 1993).

The change in experimental design to multiple-choice matching in Blocks $\mathrm{H}-\mathrm{Q}$ clearly had a negative effect on the seal's performance, since the learning criterion in Block $\mathrm{H}$ was reached only after 17 sessions, in spite of the use of objects already familiar to the seal from the twoalternative matching. However, as it did during Blocks $\mathrm{C}-\mathrm{G}$, our seal mastered the new kind of matching procedure in a rather quick learning process, indicated by the steadily decreasing numbers of sessions necessary for reaching the criterion during Blocks $\mathrm{I}-\mathrm{M}(7,5,3,2$, and 2 sessions, respectively). The seal's final performance, reaching the criterion immediately in the first two sessions of Blocks $\mathrm{L}$ and $\mathrm{M}$, was in no way impaired when completely new objects were introduced in Blocks $\mathrm{N}$ and O. Although the seal might have already been applying a concept-like rule during these blocks, we conducted a final transfer test with one-trial problems to exclude any other explanation than the formation of a sameness concept. In fact, it has been repeatedly stated that to prove a generalized matching concept, a sufficiently large sample size of first-trial data is necessary (Kastak \& Schusterman, 1992; Oden, Thompson, \& Premack, 1988; Schusterman \& Kastak, 1993; Thomas \& Noble, 1988). In preparation for this final transfer test, we conducted two sessions with problems composed of all 38 familiar objects. The seal's performance of $>80 \%$ correct choices in both sessions was considered a good basis for the final transfer test.

The seal's performance of $80 \%$ correct choices in this transfer test of 20 problems composed of 80 unfamiliar objects demonstrates formation of a sameness concept. It would be difficult to conceive that any solution to the matching task other than a sameness concept could explain both the highly significant performance of our seal ( $80 \%$ correct choices) as well as the remaining $20 \%$ of errors. The 80 test objects were sufficiently diverse across physical parameters such as size, shape, color, surface texture, and orientation to exclude stimulus-specific cuing. The 20 objects used as correct stimuli in the one-trial tests did not share any systematic parameter (e.g., a common brightness, size, or other quality) that could have been used as a cue. Such a cue would have to have been present in the 16 objects correctly chosen by our seal (or at least in a sufficiently large number of them to make the remaining correct choices possible by chance) but absent in the comparison objects. In addition, given that the stimuli were completely new, such a cue would have to have been easily detectable within a few trials of trial and error in order to make the task still solvable while maintaining $80 \%$ correct choices in the test session. These restrictions seem rather implausible.

Thus, our results show that harbor seals are capable of processing complex visual information on a conceptual level, adding the harbor seal to the list of species that have shown concept learning (for reviews, see, e.g., Roitblat \& von Fersen, 1992; Thompson, 1995; Wright, Santiago, Urcuioli, \& Sands, 1983).

\section{Some Implications of the Results for Concept Formation in Marine Mammals}

The difficulties of showing visual concept formation in harbor seals, as found by Renouf and Gaborko (1988, 1989), have been assigned to either the seals' failure to grasp the concept of sameness or the idea that the matching-to-sample paradigm might not be an appropriate vehicle for the demonstration of such a conceptualization. Similarly, Hanggi and Schusterman (1995) concluded that the standard methods of training conditional discriminations, which are successful with sea lions, might not be appropriate for harbor seals. These authors suggested that methods should instead be used that address the behavioral and ecological characteristics of this species. This kind of ecological argumentation, which classifies harbor seals as spatially adapted cognitive multimodalists capable of concept formation primarily if more than one sensory channel is involved, resembles some interpretations of early dolphin cognition studies. Because of the remarkable development of their hearing and sound-production systems and because the underwater world favors sound as an information or communication channel, dolphins were classified as acoustic specialists, and many early cognitive studies were done with respect primarily to the auditory sense (for a review, see Schusterman et al., 1986). However, Herman (1990) reported that dolphins are capable of reasonably good performance in visual cognitive tasks, thus correcting his earlier classification that the visual system of these marine mammals is constrained to serve environmental - rather than cognitive - function (Herman, 1980). In fact, more recent studies have shown that dolphins are also capable of some visual and cross-modal concept for- 
mation (see, e.g., Harley, Putman, \& Roitblat, 2003; Harley et al., 1996; Harley, Xitco, \& Roitblat, 1995; Herman et al., 1989; Mercado et al., 2000).

It has been stated that poor performance of test animals during acquisition of discrimination tasks can be due to obvious conflicts between the experimental paradigm and the animal's natural behavior (Harrison, 1992). Similarly, and as in studies that sought to demonstrate identity concept formation in sea lions (Kastak \& Schusterman, 1994; Pack et al., 1991), our harbor seal did not spontaneously apply an identity concept, but showed concept formation only after extensive training and repeated introduction of new stimulus sets. Nevertheless, our present results show that no conflict exists between visual identity matching and the sensory and cognitive adaptations of harbor seals to their aquatic environment. Moreover, our use of a multiplechoice matching task certainly fostered the seal's choosing based on the appropriate stimulus and not on exclusion or some other strategy that hindered the formation of a generalized identity concept (cf. Sidman, 1987).

However, although the conditions required for experimental evidence of identity concept formation (i.e., the conditionality and similar history of stimuli and a sufficiently large sample size of first-trial data; see, e.g., Kastak \& Schusterman, 1992; Schusterman \& Kastak, 1995 ) were met in the present examination, these conditions are in fact not very likely to occur in the wild. This lack of a natural application for concepts in an animal's environment might also lead to the difficulties that have been encountered during some experiments. It has been suggested that the most appropriate methods for studying animal cognition are those derived from the natural context, where the cognitive competence of interest is most likely to yield a fitness advantage for a particular species (Delius, 1994). It is therefore interesting to speculate about the adaptive value of an identity concept in the marine environment.

Assuming that a phylogenetically more primitive - and more ancient-familiar-novel discrimination is the natural antecedent of same-different conceptualization, Delius (1994) also mentioned some evolutionary selection pressures that might take the competence of identity-oddity recognition to a more advanced stage. For example, a predator's foraging success hunting gregarious prey could be enhanced by detecting slightly aberrant (i.e., ill or otherwise weak) individuals; this detection could be performed on the basis of a same-different discrimination. However, harbor seals, like many other marine mammal species, are known to be prey generalists, feeding on a variety of both pelagic and benthic prey. Thus, the strategy described above could be advantageous for only a portion of their prey spectrum. To our knowledge, the foraging strategies of harbor seals hunting swarm fish such as herring have not been described in detail (for reviews of marine mammal feeding ecology, see Bowen, Read, \& Estes, 2002). However, it does not seem very likely that separating and hunting down individual aberrant fish from the swarm would be an efficient strategy for seals, primarily for two reasons. First, in contrast to the body size relationship between some cooperatively hunting terrestrial predators and their comparatively large prey species, most potential prey fish are of rather small size, resulting in the need to capture many prey fish, not only single weak individuals. Second, the three-dimensional environment underwater allows all degrees of freedom for prey fish to escape when separated from the swarm, which would rather limit the chances of a predator to be successful. Indeed, it has been observed that marine mammals try to concentrate whole schools of fish near the water surface, where escape is more difficult, or to chase fish onto mud banks to capture them. Thus, there seems to be no obvious adaptive value for foraging seals in applying an identity-oddity concept to the detection of aberrant individuals.

Of course, it should be expected that other ecological applications of an identity-oddity concept could result in a fitness increase for marine mammals, but another interpretation should at least be taken into consideration. Another psychological twin phenomenon has been thought to be of adaptive value with respect to this particular visual environment - mental rotation and rotational invariance. Although this matter still seems unresolved as well, there is some evidence that the special demands of the marine environment may have only slightly modified, rather than completely changed or even eradicated, the ancient way of visual information processing that had probably already evolved in the terrestrial ancestors of marine mammals (Mauck \& Dehnhardt, 1997; Stich et al., 2003). Likewise, as a nearby psychological descendent of the phylogenetically ancient capability to conceptualize familiarity and novelty, the capability to form an abstract concept of sameness might simply be indicative of a highly developed information processing system, and the generally resulting cognitive economy in decision processes could be adaptive per se. Using an appropriate method such as a multiple-choice matching, the capability to conceptualize identity or oddity could be experimentally demonstrable both in other marine mammal species - simply because there was no need to select against this trait in the marine environment - as well as in other animals that have been assumed incapable of this conceptualization.

\section{REFERENCES}

Bowen, W. D., Read, A. J., \& Estes, J. A. (2002). Feeding ecology. In A. R. Hoelzel (Ed.), Marine mammal biology: An evolutionary approach (pp. 217-246). Oxford: Blackwell.

Delius, J. D. (1994). Comparative cognition of identity. In P. Bertelson, P. Eelen, \& G. d'Ydewalle (Eds.), International perspectives on psychological science: Vol. 1. Leading themes (pp. 25-40). Hillsdale, NJ: Erlbaum.

Domuan, M. (1998). The principles of learning and behavior (4th ed.). Pacific Grove, CA: Brooks/Cole.

DUKAS, R. (1998). Cognitive ecology: The evolutionary ecology of information processing and decision making. Chicago: University of Chicago Press.

Gellerman, L. W. (1933). Chance orders of alternating stimuli in visual discrimination experiments. Journal of Genetic Psychology, 42, 206-208.

HangGi, E. B., \& Schusterman, R. J. (1995). Conditional discrimination learning in a male harbor seal (Phoca vitulina). In R. A. Kastelein, J. A. Thomas, \& P. E. Nachtigall (Eds.), Sensory systems of aquatic mammals (pp. 543-559). Woerden, The Netherlands: De Spil. 
Harley, H. E., Putman, E. A., \& Roitblat, H. L. (2003). Bottlenose dolphins perceive object features through echolocation. Nature, $\mathbf{4 2 4}$, 667-669.

Harley, H. E., Roitblat, H. L., \& Nachtigall, P. E. (1996). Object representation in the bottlenose dolphin (Tursiops truncatus): Integration of visual and echoic information. Journal of Experimental Psychology: Animal Behavior Processes, 22, 164-174.

Harley, H. E., Xitco, M. J., JR., \& Roitblat, H. L. (1995). Echolocation, cognition, and the dolphin's world. In R. A. Kastelein, J. A. Thomas, \& P. E. Nachtigall (Eds.), Sensory systems of aquatic mammals (pp. 529-542). Woerden, The Netherlands: De Spil.

Harlow, H. F. (1949). The formation of learning sets. Psychological Review, 56, 51-65.

HARRISON, J. M. (1992). Avoiding conflicts between the natural behavior of the animal and the demands of discrimination experiments. Journal of the Acoustical Society of America, 92, 1331-1345.

Healy, S., \& Braithwaite, V. (2000). Cognitive ecology: A field of substance? Trends in Ecology \& Evolution, 15, 22-26.

Herman, L. M. (1980). Cognitive characteristics of dolphins. In L. M. Herman (Ed.), Cetacean behavior: Mechanisms and functions (pp. 363-429). New York: Wiley.

Herman, L. M. (1990). Cognitive performance of dolphins in visually guided tasks. In J. A. Thomas \& R. A. Kastelein (Eds.), Sensory abilities of cetaceans: Laboratory and field evidence (pp. 455-462). New York: Plenum.

Herman, L. M., Hovancik, J. R., Gory, J. D., \& Bradshaw, G. L. (1989). Generalization of visual matching by a bottlenose dolphin (Tursiops truncatus): Evidence for invariance of cognitive performance with visual and auditory materials. Journal of Experimental Psychology: Animal Behavior Processes, 15, 124-136.

Herman, L. M., Pack, A. A., \& Hoffmann-Kuhnt, M. (1998). Seeing through sound: Dolphins (Tursiops truncatus) perceive the spatial structure of objects through echolocation. Journal of Comparative Psychology, 112, 292-305.

Kastak, D., \& Schusterman, R. J. (1992). Comparative cognition in marine mammals: A clarification on match-to-sample tests. Marine Mammal Science, 8, 414-417.

Kastak, D., \& Schusterman, R. J. (1994). Transfer of visual identity matching-to-sample in two California sea lions (Zalophus californianus). Animal Learning \& Behavior, 22, 427-435.

MaucK, B., \& DehnhardT, G. (1997). Mental rotation in a California sea lion (Zalophus californianus). Journal of Experimental Biology, 200, 1309-1326.

Mercado, E., III, Killebrew, D. A., Pack, A. A., Mácha, I. V. B., \& Herman, L. M. (2000). Generalization of "same-different" classification abilities in bottlenosed dolphins. Behavioural Processes, 50, 79-94.

Mobley, J. R., JR., \& Helweg, D. A. (1990). Visual ecology and cognition in cetaceans. In J. A. Thomas \& R. A. Kastelein (Eds.), Sensory abilities of cetaceans: Laboratory and field evidence (pp. 519-536). New York: Plenum.

Oden, D. L., Thompson, R. K. R., \& Premack, D. (1988). Spontaneous transfer of matching by infant chimpanzees (Pan troglodytes). Journal of Experimental Psychology: Animal Behavior Processes, 14, 140-145.

Pack, A. A., \& Herman, L. M. (1995). Sensory integration in the bottlenosed dolphin: Immediate recognition of complex shapes across the senses of echolocation and vision. Journal of the Acoustical Society of America, 98, 722-733.

Pack, A. A., Herman, L. M., \& Roitblat, H. L. (1991). Generalization of visual matching and delayed matching by a California sea lion (Zalophus californianus). Animal Learning \& Behavior, 19, 37-48.

ReAL, L. A. (1993). Toward a cognitive ecology. Trends in Ecology and Evolution, 8, 413-417.

Renouf, D. (1991). Sensory reception and processing in Phocidae and Otariidae. In D. Renouf (Ed.), The behaviour of pinnipeds (pp. 345394). London: Chapman \& Hall.
Renouf, D., \& Gaborko, L. (1988). Spatial matching to sample in harbour seals (Phoca vitulina). Biology of Behaviour, 13, 73-81.

Renouf, D., \& Gaborko, L. (1989). Spatial and visual rule use by harbour seals (Phoca vitulina). Biology of Behaviour, 14, 169-181.

Rensch, B. (1973). Gedächtnis, Begriffsbildung und Planhandlungen bei Tieren. Berlin: Parey.

Roitblat, H. L. (1987). Introduction to comparative cognition. New York: Freeman.

Roitblat, H. L., \& von Fersen, L. (1992). Comparative cognition: Representations and processes in learning and memory. Annual Review of Psychology, 43, 671-710.

Rosch, E. (1978). Principles of categorization. In E. Rosch \& B. B. Lloyd (Eds.), Cognition and categorization (pp. 27-48). Hillsdale, NJ: Erlbaum.

Schusterman, R. J. (1981). Behavioral capabilities of seals and sea lions: A review of their hearing, visual, learning and diving skills. Psychological Record, 31, 125-143.

Schusterman, R. J., Gisiner, R., Grimm, B. K., \& Hanggi, E. B. (1993). Behavior control by exclusion and attempts at establishing semanticity in marine mammals using match-to-sample paradigms. In H. L. Roitblat, L. M. Herman, \& P. E. Nachtigall (Eds.), Language and communication: Comparative perspectives (pp. 249-275). Hillsdale, NJ: Erlbaum.

Schusterman, R. J., \& KastaK, D. (1993). A California sea lion (Zalophus californianus) is capable of forming equivalence relations. Psychological Record, 43, 823-829.

Schusterman, R. J., \& KASTAK, D. (1995). There is no substitute for an experimental analysis of marine mammal cognition. Marine Mammal Science, 11, 263-267.

Schusterman, R. J., \& KastaK, D. (2002). Problem solving and memory. In A. R. Hoelzel (Ed.), Marine mammal biology: An evolutionary approach (pp. 371-387). Oxford: Blackwell Science.

Schusterman, R. J., Reichmuth, C. J., \& Kastak, D. (2000). How animals classify friends and foes. Current Directions in Psychological Science, 9, 1-6.

Schusterman, R. J., Reichmuth Kastak, C., \& Kastak, D. (2002). The cognitive sea lion: Meaning and memory in the lab and in nature. In M. Bekoff, C. Allen, \& G. M. Burghardt (Eds.), The cognitive animal: Empirical and theoretical perspectives on animal cognition (pp. 217-228). Cambridge, MA: MIT Press.

Schusterman, R. J., Thomas, J. A., \& Wood, F. G. (1986). Dolphin cognition and behavior: A comparative approach. Hillsdale, NJ: Erlbaum.

Sidman, M. (1987). Two choices are not enough. Behavior Analysis, 22, $11-18$

Stich, K.-P., Dehnhardt, G., \& Mauck, B. (2003). Mental rotation of perspective stimuli in a California sea lion (Zalophus californianus). Brain, Behavior \& Evolution, 61, 102-112.

Thomas, R. K., \& Noble, L. M. (1988). Visual and olfactory oddity learning in rats: What evidence is necessary to show conceptual behavior? Animal Learning \& Behavior, 16, 157-163.

THOMPSON, R. K. R. (1995). Natural and relational concepts in animals. In H. L. Roitblat \& J.-A. Meyer (Eds.), Comparative approaches to cognitive science (pp. 175-224). Cambridge, MA: MIT Press.

von Fersen, L., Manos, C. S., Goldowsky, B., \& Roitblat, H. L. (1992). Dolphin detection and conceptualization of symmetry. In J. A. Thomas, R. A. Kastelein, \& A. Y. Supin (Eds.), Marine mammal sensory systems (pp. 733-762). New York: Plenum.

Wright, A. A., Santiago, H. C., Urcuioli, P. J., \& Sands, S. F. (1983). Monkey and pigeon acquisition of same/different concept using pictorial stimuli. In M. L. Commons, R. J. Herrnstein, \& A. R. Wagner (Eds.), Quantitative analyses of behavior: Vol. 4. Discrimination processes (pp. 295-317). Cambridge, MA: Ballinger.

(Manuscript received October 26, 2004; revision accepted for publication February 24, 2005.) 